\title{
An Analysis of Critical Thinking skills in General Education Course
}

\author{
Kattakamon Pislae-ngam \\ Office of General Education \\ Valaya Alongkorn Rajabhat University under the Royal Patronage, Thailand
}

\begin{abstract}
Critical thinking is an important skill that students need to be developed along with learning. The purpose of this research was to analysis of critical thinking skills in General Education course. The samples consisted of 132 students were selected by the cluster sampling technique. who studied in undergraduate students registered in General Education course first semester academic year 2017. The instruments used in the research were questionnaire. The findings of the study indicated that the overall critical thinking skills of students in General Education course are in the fair degree with average scores ranging from $16-20$ for $38.63 \%$. There are $9.09-22.72 \%$ students who required to make improvements in their critical thinking skill. The results from the study of each elements revealed that the students in General Education course are able to make the highest scores $21.97 \%$ and lowest scores 3.79 in awareness of uncertainties based on logic. in identifying the unmentioned statements and assumptions. Thus, the results can be developed and inserted in the teaching and learning in the next course.
\end{abstract}

Keywords: Analysis, Critical Thinking skills, Experts, General Education

\section{INTRODUCTION}

The enhancement of thinking and intellectual skills are significant and essential to the field of education. They are the key elements to the improvement of higher education population. These enhancements are consistent with the education management approach for population enhancement in accordance with the core subject stated in the National Education Plan of Thailand regarding the necessity of population enhancement to achieve the skill of critical thinking, know how to do and gain the ability to solve problems as well as the training for skills relating to the thinking process, management, practical confrontation, and the implementation of knowledge in problems prevention and solution. The principle of thinking process enhancement teaching stated, "one of the key matter to education reform is the transformation of traditional learning process by aiming to enable the learners to acquire abilities of thinking, analyzing and knowledge formation...". The critical thinking is also the crucial tools in education and way of life. In this 21st century, The education systems of every countries are urging the educational improvements and enhancements as an essential, effective driving force for the development of a country.

The same goes for Thailand under the governing of central administration. Poonsok Udom (cited in Thakorn Sitthichok)23 has mentioned about the education management in the second decade the Ministry of Education has introduced the second decade's education reform policy 2009-2018 with the vision of "Thai people are provided with the opportunity of effective, lifelong learning". The enhancement of critical thinking skills, therefore, is the obligation of instructors in optimally teaching techniques and methods to learners as well as to encourage 
the learners to acquired the complex thinking process with the abilities to accurately make the decisions and solving problems.

Thinking is the unique attribute which differentiate humans from other animals. Humans' brains are used for thinking based on logic and appropriate discretion. Individuals with such qualities shall be recognized by the society and thus become the leader toward advancement in accordance with the concept introduced who suggested that thinking is humans' essential tool which provide them with the visionary and enable humans to manage themselves in accordance with their purposes. In the addition, thinking enables humans to reflect on their choices and consequences which make them become sensible and always aware of their actions. Regarding the critical thinking, the Office of the Basic Education Commission has defined it as the crucial element to logical, prudent contemplation based on the evidence and argument associated with the relevant matters. The critical thinking is starting from the complicated and complex situation and ended up with the logical contemplation to prioritize the matters before adhere to or taking such actions. Critical thinking is the judgement with the goal of self-supervision as the result of interpretation, analysis, assessment, summarization, reference, explanation and self-regulation in thinking with circumspection of data. Furthermore, numerous define critical thinking as mainly associated with thinking and decision making as well as the thinking based on knowledge and logical determination. Ennis has described the critical thinking as the process which required both knowledge and skills in deciding what to do. Critical thinking is the reasonable reflective thinking that is focused on what to believe. This is in line with Moore and Parker's definition of critical thinking as the careful, deliberate determination of whether one should accept, reject, or suspend judgment about a claim and the degree of confidence with which one accepts or rejects it. Critical thinking is crucial to the fulfillment of individuals' functions and essential to effective participation in the democratic society based on the notion in which actions and beliefs of the individuals are mutually related. Individuals' beliefs toward certain matters shall define their actions or inactions. Nevertheless, the most vital thing is the sensible and logical reflection to decide what to belief and do. Critical thinking is purposive thinking with self-decision and supervision based on the reasons reflected from evidences, substances, notions, methods and principles which is consistent with individuals' characteristics in the learning-based society.

The critical thinking is, therefore, the important skill for the learning management in general education course which focused on integrated teaching based on project. The learners have progressive learning process in thinking. It is the duty of instructors to develop such skills to the learners. Critical thinking consists of educable various thinking skills and every skills are equally crucial and beneficial. Critical thinking is part of the modes of thinking in addition to thinking, creativity, decision making and problem solving which required the orderly thinking from lower to higher levels; recall, interpretation, comparison, classification, summarization, reference, assumption forming, prediction, analysis, synthesis, and assessment. These skills will provide the learners with effective learning and served as the promising fundamental to the implementation in other subjects.

\section{LITERATURE REVIEW}

Critical thinking is thinking with a purpose Facione 10 Ennis 6 defines it as "reasonable, reflective thinking focused on deciding what to believe or do" (our emphasis). Gambrill describes it as thinking in a purposeful way using an array of standards such as clarity, fairness, precision, accuracy, logic and relevancy. Some see critical thinking as a natural attribute, like intelligence, others see it as a set of skills that can be learned and followed. The more contemporary view is that critical thinking is a process that includes both cognitive and affective domains of reasoning Facione10 McPeck18 Gambrill13 Ennis9 Accordingly, critical 
thinking is a combination of attributes and skills, which can be enhanced through an improved understanding of its centrality to ethically and intellectually rigorous practice, whether in medicine, nursing, social work, sports coaching or teaching history Ennis 8; Facione 11. This adds a moral and ethical dimension to critical thinking: the purpose or reasoning behind critical thinking is seen as the development of a better world, one that is humane and just. Thus, critical thinking is not just an intellectual exercise in problem solving but has a value base that aims to improve human functioning, safety, health and emotional well-being Gambrill 13. It is about sense-making as much as it is about problem-solving.

Conceptualizing critical thinking as a composite of knowledge, skills and attitudes means that knowing our own limitations, the stereotypes we hold, our cultural biases and our own personal style of thinking is essential. Emotion - your own feelings, beliefs and values - is an important influence on the critical thinking process Brookfield 2 Gambrill 13 For social workers, this means being aware of one's own values, beliefs and prejudices and also being able to empathize with, listen to, and incorporate the views and voices of the people with whom one works. According to Facione10, the personal dispositions or characteristics of openmindedness, respect, tolerance and empathy are as important for critical thinking as the cognitive skills of intellectual curiosity, integrity and discipline. Critical thinking needs to include knowledge of oneself, as well as the ability to understand the bigger picture by learning from people from different cultures, backgrounds and worldviews. Self-knowledge is positioned as one of the three forms of knowledge central to critical thinking, the others being content knowledge and performance knowledge identifies eight characteristics of critical thinking. Critical thinking involves asking questions, defining a problem, examining evidence, analyzing assumptions and biases, avoiding emotional reasoning, avoiding oversimplification, considering other interpretations, and tolerating ambiguity. Dealing with ambiguity is also seen by Walker cited in Jones A.15 as an essential part of critical thinking, "Ambiguity and doubt serve a critical-thinking function and are a necessary and even a productive part of the process" Another characteristic of critical thinking identified by many sources is metacognition. Metacognition is thinking about one's own thinking. More specifically, "metacognition is being aware of one's thinking as one performs specific tasks and then using this awareness to control what one is doing"

In the book, Critical Thinking, Beyer cited in Joe Lau \& Jonathan Chan14 elaborately explains what he sees as essential aspects of critical thinking. These are:

Dispositions: Critical thinkers are skeptical, open-minded, value fair-mindedness, respect evidence and reasoning, respect clarity and precision, look at different points of view, and will change positions when reason leads them to do so.

Criteria: To think critically, must apply criteria. Need to have conditions that must be met for something to be judged as believable. Although the argument can be made that each subject area has different criteria, some standards apply to all subjects. "... an assertion must... be based on relevant, accurate facts; based on credible sources; precise; unbiased; free from logical fallacies; logically consistent; and strongly reasoned"

Argument: Is a statement or proposition with supporting evidence. Critical thinking involves identifying, evaluating, and constructing arguments.

Reasoning: The ability to infer a conclusion from one or multiple premises. To do so requires examining logical relationships among statements or data. 
Point of View: The way one views the world, which shapes one's construction of meaning. In a search for understanding, critical thinkers view phenomena from many different points of view.

Procedures for Applying Criteria: Other types of thinking use a general procedure. Critical thinking makes use of many procedures. These procedures include asking questions, making judgments, and identifying assumptions.

Critical thinking is a metacognitive skill. What this means is that it is a higher-level cognitive skill that involves thinking about thinking. We have to be aware of the good principles of reasoning and be reflective about our own reasoning. In addition, we often need to make a conscious effort to improve ourselves, avoid biases, and maintain objectivity. This is notoriously hard to do. We are all able to think but to think well often requires a long period of training.

The experts define self-regulation to mean "self-consciously to monitor one's cognitive activities, the elements used in those activities, and the results educed, particularly by applying skills in analysis, and evaluation to one's own inferential judgments with a view toward questioning, confirming, validating, or correcting either one's reasoning or one's results." Kilroy17 the two sub-skills here are self-examination and self-correction. Examples? Easy to examine your views on a controversial issue with sensitivity to the possible influences of your personal biases or self-interest, to check yourself when listening to a speaker in order to be sure you are understanding what the person is really saying without introducing your own ideas, to monitor how well you seem to be understanding or comprehending what you are reading or experiencing, to remind yourself to separate your personal opinions and assumptions from those of the author of a passage or text, to double check yourself by recalculating the figures, to vary your reading speed and method mindful of the type of material and your purpose for reading, to reconsider your interpretation or judgment in view of further analysis of the facts of the case, to revise your answers in view of the errors you discovered in your work, to change your conclusion in view of the realization that you had misjudged the importance of certain factors when coming to your earlier decision.

Finally, as mentioned earlier, psychologists have discovered over the years that human reasoning can be easily affected by all kinds of cognitive biases. For example, people tend to be over-confident of their abilities, and focus too much on evidence that supports their preexisting opinions. We should be alert to these biases in our attitudes towards our own thinking.

\section{Participants}

\section{METHODOLOGY}

The populations in this research were the first-year students who registered in the General Education course in the first semester of academic year 2017, Rajabhat University. The samples were 132 students (Male $=60$, Female $=72$ ) with the population of 1320 students selected by the Cluster Random Sampling technique.

\section{Method and design}

The research design was a Research and Development. It originated with the investigation of critical thinking skill of the students in General Education course. The study consisted of two phases;

The first phase: designing the Critical Thinking test. the details of proceeding in the first phase are discussed below; 
1. The instruments used in the research were examining the definitions of "Critical Thinking" and "Elements of the Critical Thinking".

2. Determine the elements of critical thinking in the form of codes for the ease of assessment by the specialists as shown in Table 1 .

Table 1 The elements are fundamentals to the existence

\begin{tabular}{|l|l|}
\hline Advanced Thinking Skills & \multicolumn{1}{|c|}{ The element of Critical Thinking skills } \\
\hline \multirow{5}{*}{ Critical Thinking Skills } & 1. Distinguishing facts from opinions = T1 \\
\cline { 2 - 3 } & 2. The verification for source credibility = T2 \\
\cline { 2 - 3 } & 3. Contemplation of validity based on facts = T3 \\
\cline { 2 - 3 } & 4. Distinguishing information from opinions = T4 \\
\cline { 2 - 3 } & 5. Identifying biases or prejudices = T5 \\
\cline { 2 - 3 } & 6. Identifying the unmentioned statements and assumptions=T6 \\
\cline { 2 - 3 } & 7. Identifying the ambiguous opinions or arguments = T7 \\
\cline { 2 - 3 } & 8. Distinguishing accuracy-verifiable opinions=T8 \\
\cline { 2 - 3 } & 9. Awareness of uncertainties based on logic=T9 \\
\cline { 2 - 3 } & 10. The contemplation for the stability in arguments or opinions = T10 \\
\hline
\end{tabular}

3. The test designed by the author has been brought to five specialists for the inspection of Index of Item Objective Congruence (IOC) between the test questions and objectives, the IOC between test questions and the elements of critical thinking, and the language usage of all 30 items of the test. The assessment results from the specialists revealed that the IOC between test questions and the elements of critical thinking and the language usage were 0.6-1.0 The confidence interval of the test has been calculated using the KR-20 Kuder-Richardson Formula, which is found to be 0.93 for the entire test. The author has made revisions to some of the improper tests and the tests with suitable difficulty levels, discrimination, and desirable quantity was selected.

The Second phase: data collection and analysis. The designed tests have been distributed to 132 students of the General Education course to collect the data.

1. The gathered data then being analyzed and summarize.

2. The interviews were conducted with five experts who had more than ten years of teaching experience.

\section{Data Analysis}

The data were collected from quantitative analysis from frequency, mean, standard deviation and the quality of the interview.

\section{RESULT}

The results from the study of critical thinking attributes of 132 students in the General Education course indicated that the average score for the critical thinking skill of the sample students was 30 The highest score acquired by the student was 27.50 the lowest score was 9.50 with the standard deviation of 3.47 The analysis performed has classified the capacity levels regarding the critical thinking skill of the students on the percentage basis. The results were detailed in Table 2 . 
Table 2 The levels of critical thinking skill of the students in the General Education course

\begin{tabular}{|c|c|c|c|}
\hline Score & $\begin{array}{c}\text { Level of critical thinking } \\
\text { skills }\end{array}$ & $\mathrm{n}$ & Percentage \\
\hline $26-30$ & Excellence & 14 & 10.60 \\
\hline $21-25$ & Good & 25 & 18.93 \\
\hline $16-20$ & Fair & 51 & 38.63 \\
\hline $11-15$ & Poor & 30 & 22.72 \\
\hline $0-10$ & Very poor & 12 & 9.09 \\
\hline
\end{tabular}

The finding in table 2 revealed that there are $10.60 \%$ students who acquired the excellence degree of critical thinking scores, 18.93 of the students acquired the good degree of critical thinking scores, and $38.6 \%$ of the students acquired the fair degree of critical thinking scores. There are $9.09-22.72 \%$ students who required to make improvements in their critical thinking skill.

The findings from the investigation of levels of critical thinking skill according to the elements of critical thinking, which including 1) distinguishing facts from opinions; 2) the verification for source credibility; 3) contemplation of validity based on facts; 4) distinguishing information from opinions; 5) identifying biases or prejudices; 6) identifying the unmentioned statements and assumptions; 7) identifying the ambiguous opinions or arguments; 8) distinguishing accuracy-verifiable opinions; 9) awareness of uncertainties based on logic; and 10) the contemplation for the stability in arguments or opinions, were showed in the Table 3

Table 3 The findings details according to the elements of critical thinking.

\begin{tabular}{|l|l|}
\hline The element of Critical Thinking skills & Percentage \\
\hline T1 Distinguishing facts from opinions & 11.36 \\
\hline T2 The verification for source credibility & 14.39 \\
\hline T3 Contemplation of validity based on facts & 6.06 \\
\hline T4 Distinguishing information from opinions & 9.09 \\
\hline T5 Identifying biases or prejudices & 9.85 \\
\hline T6 Identifying the unmentioned statements and assumptions & 21.97 \\
\hline T7 Identifying the ambiguous opinions or arguments & 12.12 \\
\hline T8 Distinguishing accuracy-verifiable opinions & 6.82 \\
\hline T9 Awareness of uncertainties based on logic & 3.79 \\
\hline T10 The contemplation for the stability in arguments or opinions & 4.55 \\
\hline
\end{tabular}

The findings in Table 3 indicated that the element of critical thinking which earned the highest scores from the students was the T6, identifying the unmentioned statements and assumptions, followed by $\mathrm{T} 2$, the verification for source credibility. The element of critical thinking which earned the lowest scores from the students was T9, awaring of uncertainties based on logic.

\section{DISCUSSION}

The study of analysis of critical thinking characteristics of students in General Education course. The author has examined the critical thinking characteristics of students in General Education course based on the concepts of various education specialists and perform the analysis to seek the suitableness for General Education course. The total of ten elements have been discovered and in line with Feely.These elements are fundamentals to the existence of critical thiking. The learners can practice and developed the following elements by themselves starting with the ability of sensible reflections from situations; 1) distinguishing facts from opinions; 2) the verification for source credibility; 3) contemplation of validity based on facts; 4) distinguishing information from opinions; 5) identifying biases or prejudices; 6) identifying the unmentioned statements and assumptions; 7) identifying the ambiguous opinions or 
arguments; 8) distinguishing accuracy-verifiable opinions; 9) awaring of uncertainties based on logic; and 10) the contemplation for the stability in arguments or opinions.

The findings of the study indicated that the overall critical thinking skills of students in General Education course are in the fair degree with average scores ranging from 16-20 for 38.63\%. The results from the study of each elements revealed that the students in General Education course are able to make the highest scores 21.97 in identifying the unmentioned statements and assumptions and lowest scores 3.79 in awareness of uncertainties based on logic. This is due to the fact that in the 21st century education setting, the learners gained better researching skills and the sources of information are more accessible and available. This is in conformity with the work of Krissana Lohakarok.21 The Study of Critical Thinking skills of Seventh Grade Hmong Hilltribe Students in Tak Province, Thailand. which discovered that the students acquired intermediate degree of critical thinking scores in the subject of database and application management and thus possessed the skill of critical thinking. The students are found to make the highest score regarding the interpretation element. Their logic is in the low degree. Siwaporn Songsaen22 The Development of Critical Thinking for early Childhood education students through MAPLE Instructional Model. revealed that the critical thinking confirmatory factors analysis model for students in the Early Childhood Education program is consist of five elements including problems defining, information contemplation, assumption, interpretation and assessment. The critical thinking skill of students in the Early Childhood Education program is perfectly conform with the empirical data. The weight of each elements is in positive with statistically significance of .01 level for every elements.

\section{CONCLUSIONS}

The study and analysis of critical thinking provide the insight on which level the learners has possessed, how is their critical thinking skill, how to be further enhance and which element that the instructors should promote to be beneficial to the learners and education management for General Education course regarding the ideal direction. It is recommended to arrange the learning activities or apply activities in the learning process to provide the learners with critical thinking skill and conforming with the education in the era of digital citizens with the integration of the advance information technology in enhancing the learning process for General Education course to encourage the critical thinking of the learners. The critical thinking, therefore, is crucial for the students in General Education course in practical thinking and the ability to solve problems in forming the systematic thinking process and advance thinking skill as well as the implementation in the daily life.

\section{References}

Alfaro-LeFevre, R. (2013). Critical thinking and clinical judgment: A practical approach to outcome focused thinking (5th ed).

Brookfield, S. D. (1987). Developing Critical Thinkers, Open University Press, Milton Keynes.

Atay, S., \& Karabacak, U. (2012). Care plans using concept maps and their effects on the critical thinking dispositions of nursing students. International Journal of Nursing Practice, 18, 233-239.doi:10.1111/j.1440172X.2012.02034.X

Daley, B. J., Morgan, S., \& Black, S. B., (2016). Concept maps in nursing education: A historical literature review and research directions. Journal of Nursing Education,55(I 11), 631-639. doi:10.3928/01484834-20161011-05

Ennis, R. H. (2013). The nature of critical thinking: An outline of critical thinking dispositions and abilities. Retrieved from www.critical thinking.net

Ennis, R. H. (1989). 'Critical thinking and subject specificity: clarification and needed research'. Educational Researcher, vol.18, 3, pp. 4-10.

Ennis, R. H. (1996). Critical Thinking. Prentice-Hall, Upper Saddle River, NJ. 
Ennis, R. H. (2002). 'A Super-streamlined Conception of Critical Thinking'. Retrieved 5 October 2017, from http://faculty.ed.uiuc.edu/rhennis/SSConcCTApr3.html

Ennis, R. H. (1985). Ennis-Weir Critical Thinking Essay Test, Retrieved 20 October 2017 from http://faculty.ed.uiuc.edu/rhennis/Assessment.html

Facione, D. P. A. (2006). 'Critical Thinking: What It Is and Why It Counts'. Retrieved 15 October 2017 from https://www.insightassessment.com/pdf_files/what\&why2009.pdf

Facione, P. A. (2013). Critical thinking: What it is and why it counts. Retrieved from http://www.insightassessment.com/CT- Resources /Teaching-For-and-About-Critical-Thinking clinical setting among nursing students. Proceedings of 6th International Conference,

Fook, J. (1996). The Reflective Researcher: Developing a Reflective Approach to Practice, Allen and Unwin, St Leonards NSW.

Gambill, E. (2006). Social Work Practice: A Critical Thinkers' Guide. Oxford University Press, Oxford.

Joe Lau \& Jonathan Chan. (2018). Review “what is critical thinking?”. Retrieved from

http://philosophy.hku.hk/think/critical/ct.php

Jones, A. (2007). 'Multiplicities or manna from heaven? Critical thinking and the disciplinary context', Australian Journal of Education, 51(1), pp.84-103.

Jones-Devitt, S. and Smith, L. (2007). Critical Thinking in Health and Social Care, Sage, London.

Kilroy, D. A. (2017). Review problem based learning. Retrieved from http://emj.bmj.com/on May 27, 2017 Published by group.bmj.com

Lin, X., Hmelo, C., Kinzer, C. K., \& Secules, T. J (1999). Designing technology to support reflection, Educational Technology Research \& Development, pp 43-62.

McPeck, J. E. (1981). Critical Thinking and Education. Robertson, Oxford.

Walker, S. E. (2004). 'Active learning strategies to promote critical thinking', Journal of Athletic Training, vol. 38, 3, pp.263-267.

Krissana Lohakarok. (2016). The Study of Critical Thinking skills of Seventh Grade Hmong Hilltribe Students in Tak Province, Journal of Education, Mahasarakham University. 11(2), pp 28-40. (Text in Thailand)

Siwaporn Songsaen. (2016). The Development of Critical Thinking for early Childhoods education students through MAPLE Instructional Model. Journal of Graduate Studies Valaya Alongkorn Rajabhat University.8(3), pp 110-129. (Text in Thailand)

Thakorn Sitthichok. (2016). Critical Thinking in Social Studies Learning Process, Faculty of Humanities and Social Sciences. Taksin University.9(2), pp 87-101. (Text in Thailand) 